in vivo $34: 255-260(2020)$

doi:10.21873/invivo.11768

\title{
Laryngeal Diffuse Large B-Cell Lymphoma Presenting as Laryngeal Stenosis
}

\author{
YAOYUN TANG ${ }^{1,2}$, PENG LI $^{1,3}$, DAVID CUA ${ }^{4}$ and JINPING LAI ${ }^{1,5}$ \\ ${ }^{1}$ Department of Pathology, Immunology and Laboratory Medicine, \\ University of Florida College of Medicine, Gainesville, FL, U.S.A.; \\ ${ }^{2}$ Department of Otolaryngology-Head and Neck Surgery, \\ Xiangya School of Medicine, Central South University, Changsha, P.R. China; \\ ${ }^{3}$ Department of Pathology, University of Utah, ARUP Laboratories, Inc., Salt Lake City, UT, U.S.A.; \\ ${ }^{4}$ Department of Otolaryngology-Head and Neck Surgery, \\ Kaiser Permanente Sacramento Medical Center, Sacramento, CA, U.S.A.; \\ ${ }^{5}$ Department of Pathology and Laboratory Medicine, \\ Kaiser Permanente Sacramento Medical Center, Sacramento, CA, U.S.A.
}

\begin{abstract}
Background: Laryngeal stenosis is challenging for treatment due to uncertain etiology. Primary laryngeal lymphoma as the initial clinical manifestation of laryngeal stenosis has been rarely reported. Primary diffuse large B-cell lymphoma as an underlying etiology has not been reported. Case Report: A 79-year-old male presented with dyspnea, stridor and dysphonia of 6 months' duration. Computed tomography scans and flexible laryngoscopic examination revealed vocal cord mobility with bilaterally limited abduction and a subglottic stenosis up to 50\%. The laryngeal mucosa was smooth. Laryngeal biopsy showed atypical lymphoid infiltrates, predominantly large sized B-cells, in the submucosa with crush/cauterized artifacts. The tumor cells were positive for B-lymphocyte antigen CD20, paired-box 5 (PAX5), B-cell lymphoma 2 (BCL2), BCL6 and multiple myeloma oncogene 1 (MUM1). They were negative for CD10, CD30, cyclin D1 (CCND1), SRY-box 11 (SOX11), activin-receptor like kinase 1 (ALK1), CD138 and c-MYC, and negative for kappa/lambda
\end{abstract}

This article is freely accessible online.

Correspondence to: Yaoyun Tang, MD, Ph.D., Department of Otolaryngology-Head and Neck Surgery, Xiangya School of Medicine, Central South University, Changsha, Hunan 410008, PR China. Tel: +86 13786189487; Fax: +86 073184327469, e-mail: tangyyent@163.com or Jinping Lai, MD, Ph.D., Department of Pathology and Laboratory Medicine, Kaiser Permanente Sacramento Medical Center, Sacramento, CA 95825, U.S.A. Tel: +1 9169737260; Fax: +1 9169737283, e-mail: Jinping.x.lai@kp.org

Key Words: Larynx, diffuse large B-cell lymphoma, DLBCL, laryngeal stenosis, Immunohistochemistry, next-generation sequencing, NGS. light chain and Epstein-Barr virus-encoded small RNA by in situ hybridization. The pathologic diagnosis was diffuse large B-cell lymphoma. Fluorescent in situ hybridization (FISH) for MYC was negative. Next-generation sequencing using a 175gene panel was performed and no pathologic mutations were identified. No lymphadenopathy elsewhere was identified. The patient was treated with chemotherapy and was doing well at the 5-month follow-up. Conclusion: To the best of our knowledge, this is the first documented case of primary laryngeal diffuse large B-cell lymphoma presenting as increasing laryngeal stenosis. The rarity, diagnosis and treatment of this entity are discussed.

Laryngeal stenosis is a common phenomenon in the Head and Neck Clinic and often causes voice change, stridor and even dyspnea $(1,2)$. It is difficult to treat due to lifethreatening symptoms of unknown etiology. Surgery, dilatation, medication including glucocorticoid, and stent implantation are the current mainstays of treatment for laryngeal stenosis but the overall effect is limited. Identification of the underlying etiology and recognition of the pathogenesis are important for treatment and improving prognosis of laryngeal stenosis.

There are many causes of laryngeal stenosis, some are difficult to determine, and the underlying etiology has been misdiagnosed in some cases, leading to inappropriate patient management (3, 4). Lymphoma causing laryngeal stricture as initial manifestation has rarely been recognized in clinical practice. As far as we are aware, there are only six cases reported in English literature, most of them are small B-cell lymphoma (5-10); patients with laryngeal stenosis caused by diffuse large B-cell lymphoma (DLBCL) have not been reported. 
in vivo $34: 255-260(2020)$

Table I. Summary of reported laryngeal stenosis caused by small B-cell lymphomas (six cases).

\begin{tabular}{|c|c|c|c|c|c|c|}
\hline Article & $\begin{array}{l}\text { Site of } \\
\text { stenosis }\end{array}$ & $\begin{array}{l}\text { Age, } \\
\text { gender }\end{array}$ & Manifestation & Pathology & Management & Prognosis \\
\hline $\begin{array}{l}\text { Bielinski et al., } \\
2014 \text { (5) }\end{array}$ & Subglottic & 88 , Female & $\begin{array}{l}\text { Progressive } \\
\text { inspiratory } \\
\text { stridor }\end{array}$ & $\begin{array}{l}\text { MZL of } \\
\text { MALT-type }\end{array}$ & $\begin{array}{l}\text { Rituximab } \\
\text { (Rituxan) } \\
\text { therapy }\end{array}$ & $\begin{array}{l}\text { Asymptomatic at } 18 \\
\text { months follow-up, } \\
\text { was still in remission. }\end{array}$ \\
\hline $\begin{array}{l}\text { Kuo et al., } \\
2011 \text { (6) }\end{array}$ & Subglottic & 50, Female & $\begin{array}{c}\text { Hoarseness, } \\
\text { stridor, and } \\
\text { dyspnea. }\end{array}$ & MALT & $\begin{array}{l}\text { Complete } \\
\text { surgical } \\
\text { excision }\end{array}$ & N/A \\
\hline $\begin{array}{l}\text { Brake et al., } \\
2011 \text { (7) }\end{array}$ & Subglottic & 57, Male & $\begin{array}{l}\text { Hoarseness, } \\
\text { foreign body } \\
\text { sensation } \\
\text { in throat }\end{array}$ & LPL & Chemotherapy & $\begin{array}{l}\text { Laryngeal lesion was } \\
\text { completely stabilized. } \\
\text { The laryngeal lesion was } \\
\text { stable at last follow-up. }\end{array}$ \\
\hline $\begin{array}{l}\text { Korst, } \\
2007 \text { (8) }\end{array}$ & Subglottic & 61 , Female & $\begin{array}{l}\text { Insidious } \\
\text { onset of } \\
\text { dyspnea }\end{array}$ & MALT & $\begin{array}{l}\text { Complete } \\
\text { surgical } \\
\text { excision }\end{array}$ & $\begin{array}{l}\text { No recurrence of tumor } \\
4 \text { months after operation }\end{array}$ \\
\hline $\begin{array}{l}\text { Steffen } \text { et al., } \\
2007(9)\end{array}$ & Subglottic & 62, Male & $\begin{array}{l}\text { Dry cough, } \\
\text { stridor and } \\
\text { exertional } \\
\text { dyspnea }\end{array}$ & $\begin{array}{l}\text { MZL of } \\
\text { MALT-type }\end{array}$ & R-CHOP & $\begin{array}{l}\text { No recurrence } \\
\text { in } 15 \text { months }\end{array}$ \\
\hline $\begin{array}{l}\text { Andratschke et al., } \\
2005(10)\end{array}$ & $\begin{array}{c}\text { Subglottic } \\
\text { Tracheal }\end{array}$ & 58, Male & Dyspnea & MZL & $\begin{array}{l}\text { Local } \\
\text { radiotherapy }\end{array}$ & $\begin{array}{l}\text { No local recurrence } \\
\text { in } 12 \text { months }\end{array}$ \\
\hline
\end{tabular}

MZL: Marginal zone B-cell lymphoma; LPL: lymphoplasmacytic lymphoma; MALT: mucosa-associated lymphoid tissue lymphoma; N/A: not applicable; R-CHOP: rituximab, cyclophosphamide, doxorubicin, vincristine and prednisone.

Here, we present a case of laryngeal stenosis as the initial manifestation caused by primary DLBCL. The patient underwent right posterior cordotomy with $\mathrm{CO}_{2}$ laser and a small part of the right vocal cord tissue was biopsied for pathological diagnosis during the laser surgery. The histological features and immunohistochemical profile supported the diagnosis of DLBCL. Cytogenetic and nextgeneration sequencing were also attempted. The rarity, diagnosis and treatment are discussed.

\section{Case Report}

A 79-year-old male was referred to the Clinic for evaluation and treatment due to increased dyspnea, stridor and dysphonia of 6 months' duration. He reported that he had had difficulty with his voice and worsening shortness of breath for about 6 months. In Spring 2018, he noticed shortness of breath and was initially diagnosed with bronchitis. The patient described his voice as being hoarse in quality, which had begun before the dyspnea. There was an increase in shortness of breath when walking, phonation and exposure to cold weather. No recent intubations for this patient were reported. The patient had past surgical histories including appendectomy and coronary artery bypass graft.

Under topical anesthesia, flexible laryngoscopy revealed a subglottic stenosis and subglottic stenosis was up to $50 \%$.
There was true vocal cord mobility with bilaterally limited abduction and there was muscle tension dysphonia. Head and neck computed tomography showed that the vocal cord tissue and subglottic area were thickened, and the glottic, especially the subglottic area, had become narrow (Figure $1 \mathrm{~A}$ and $\mathrm{B}$ ). A tentative diagnosis of laryngeal stenosis and dysphonia was made.

After obtaining informed consent, the patient was taken to the Operating Room with general anesthesia. A Dedo laryngoscope was used to obtain a full view of the bilateral true vocal cords including the anterior commissure. A zerodegree telescope was used to provide high-powered magnification. The above stenosis was noted. Using the operating microscope and a $\mathrm{CO}_{2}$ laser, right posterior cordotomy was performed. The excision was carried down to the subglottis. The excised portion of the posterior right true vocal cord was sent for pathological evaluation. A balloon dilator was then passed into the area of stenosis and inflated to a diameter of $20 \mathrm{~mm}$. It was deflated and then removed. Dilation of the stenosis was confirmed with the telescope.

Histology and immunohistochemistry. Hematoxylin and eosin-staining of sections of the right vocal cord showed fragments of squamous and glandular mucosa involved by a dense atypical lymphocytic infiltrate with crush and cauterized artifacts (Figure 1C). However, in better-preserved areas, the atypical lymphoid cells appeared intermediate to 

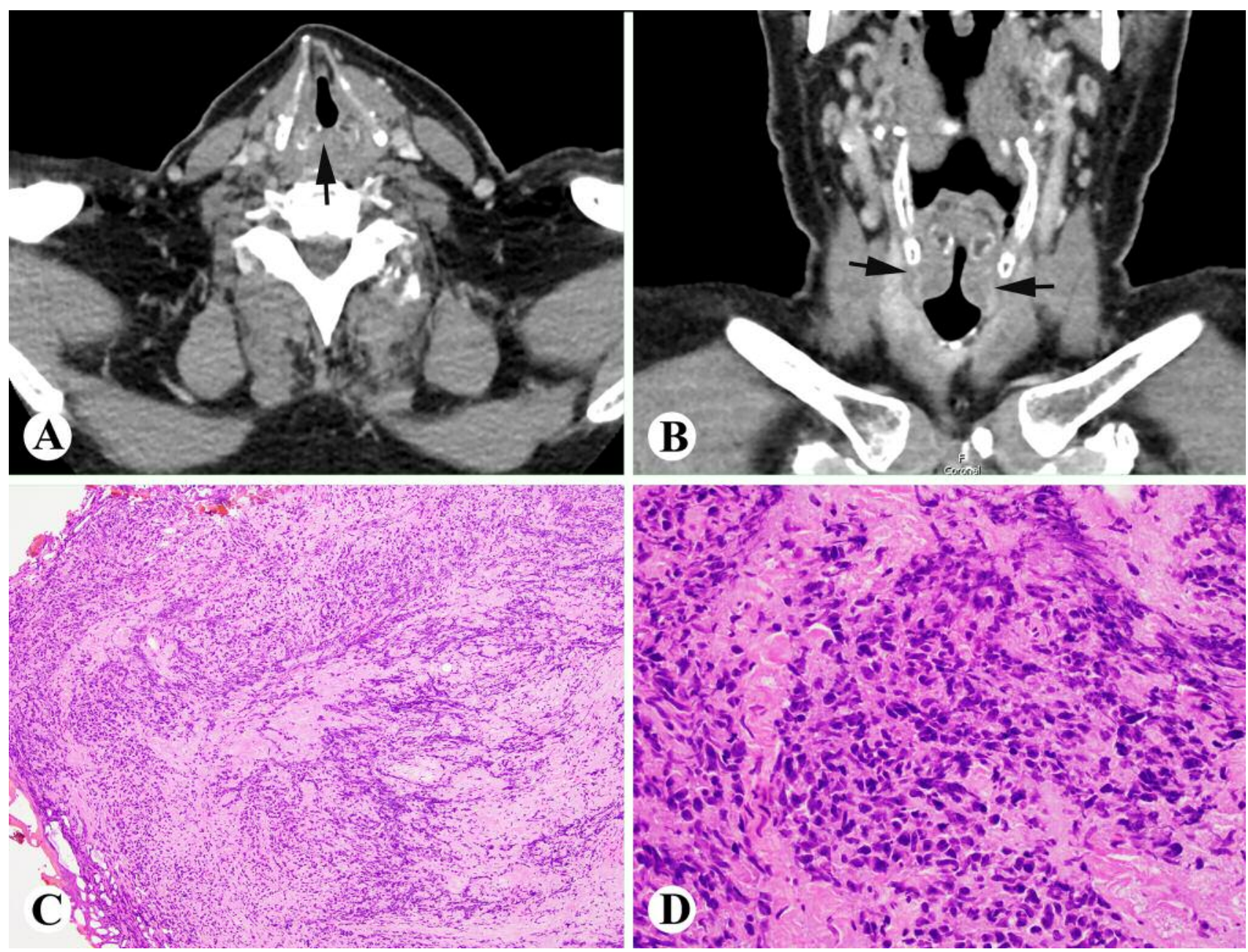

Figure 1. Computed tomographic (CT images $(A$ and $B)$ and histology $(C$ and $D)$ of our case of laryngeal stenosis. CT scans showed the subglottic narrowing $(A$, arrow) and swollen vocal cord $(B$, arrows). Hematoxylin and eosin staining of sections, showing diffuse large-sized atypical lymphoid cell infiltrate with crush and cauterized artifacts. Original magnification: $C, \times 100 ; D, \times 400$.

large in size with irregular nuclear contours (Figure 1D). By immunohistochemical staining, the atypical lymphoid cells were positive for B-lymphocyte antigen CD20 (Figure 2A), paired-box 5 (PAX5), (Figure 2B), and negative for CD3 (Figure 2C left), supporting the diagnosis of a large-cell lymphoma of B-cell origin. The tumor cells were also positive for B-cell lymphoma 2 (BCL2) (Figure 2C right), BCL6 (Figure 2D left), and multiple myeloma oncogene 1 (MUM1); and negative for CD10, CD30, cyclin D1 (CCND1), SRY-box 11 (SOX11), activin-receptor like kinase 1 (ALK1), CD138, MYC, kappa/lambda light chain, AE1/AE3 and negative Epstein-Barr virus-encoded small RNA by in situ hybridization. CD3 (Figure 2C left), CD5, and CD43 highlighted interspersed, small mature T-cells. CD21 and CD23 did not stain for follicular dendritic cell meshworks. CD138 highlighted a few, scattered plasma cells. The Ki-67 index was approximately $50-60 \%$ in the betterpreserved areas (Figure 2D right). Staining for immunoglobulin $\mathrm{G}(\mathrm{IgG})$ and $\operatorname{IgG} 4 \mathrm{a}$ did not show evidence of IgG4-related disease. In situ hybridization for kappa/lambda light chain showed polyclonal plasma cells and was negative for the tumor cells. Overall, these features supported the diagnosis of DLBCL.

Cytogenetic and molecular studies. MYC fluorescent in situ hybridization analysis was designed to detect 8q24 (MYC) translocations regardless of rearrangement partners to exclude high grade B-cell lymphoma, such as Burkitt lymphoma or high-grade B-cell lymphoma with 'double/triple hit'. Break-apart probes targeting the upstream 

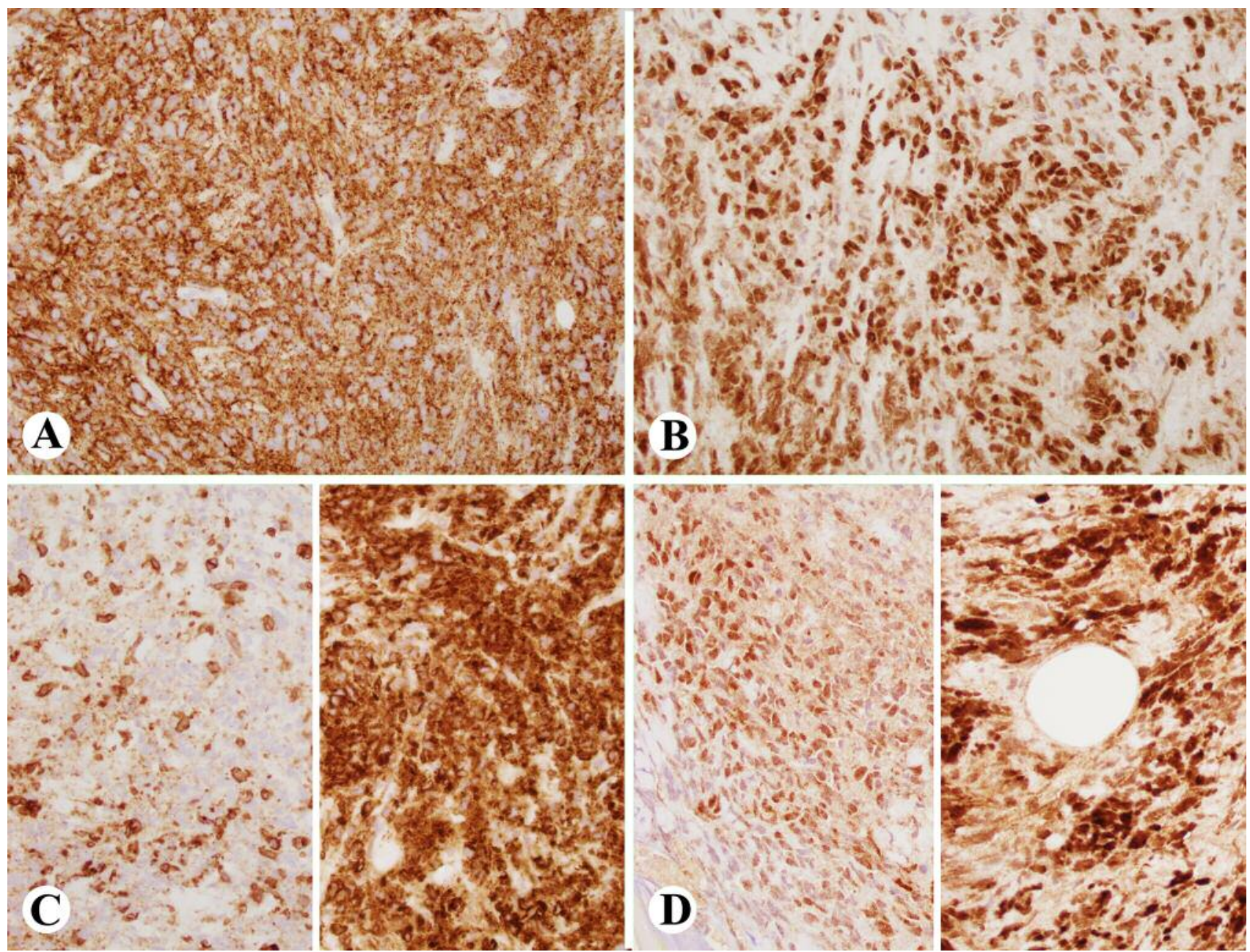

Figure 2. Immunohistochemistry of the lymphoma. The tumor cells were positive for B-lymphocyte antigen CD20 (A), paired-box 5 (B), negative for CD3 (C left), positive for B-cell lymphoma 2 (C right) and B-cell lymphoma-6 (D left). The proliferative index was $60 \%$ by Ki-67 (D right). Original magnification: $\times 400$.

(5') and downstream (3') flanking regions of the $M Y C$ gene were used (Abbott Molecular, Des Plaines, IL, USA) and no $M Y C$ rearrangement was identified in this specimen by counting at least 200 cells. Thus, this lymphoma was best classified as DLBCL, not otherwise specified.

Next-generation sequencing using a 175-gene panel was also performed for somatic mutations, and no pathological mutations were identified.

Treatment decision. After a Multidisciplinary Tumor Board discussion, the patient was treated with chemotherapy with monoclonal antibodies to CD20 (rituximab), cyclophosphamide, adriamycin, vincristine and prednisone (RCHOP) regimens. At the 5-month follow up the patient was doing well and compliant with the chemotherapy.

\section{Discussion}

Common causes of laryngeal stenosis include, but are not limited to, infection, trauma, surgery, congenital malformation, autoimmune disease and neoplasms. One of the most common causes of laryngeal stenosis is neoplasm or fibrosis scar formation secondary to tumor treatment. Primary laryngeal lymphoma is rarely reported as the underlying etiology of laryngeal stenosis.

Among the six cases of B-cell lymphomas that have been reported to have caused laryngeal stenosis, five were marginal zone lymphoma of mucosa-associated lymphoid tissue lymphoma (MALT) and one was lymphoplasmacytic lymphoma (5-10) (Table I). Andratschke et al. reported a 58year-old male patient with gradually aggravated dyspnea and 
subglottic stenosis (10). The patient was diagnosed pathologically as small B-cell lymphoma and treated with radiotherapy. There was no local recurrence of the tumor during the follow-up period reported in the literature. Brake et al. reported a 57-year-old male patient with hoarseness and foreign body sensation in his larynx. Endoscopic and imaging findings suggested subglottic stenosis (7). Pathological diagnosis of laryngeal lesions was lymphoplasmacytic lymphoma and his laryngeal stenosis were controlled by chemotherapy. The other four patients also showed subglottic stricture and were pathologically diagnosed with MALT. Among them, two underwent endoscopic resection only; there was no local recurrence after short-term follow-up in one, and the other study failed to report the follow-up results. The other two patients received chemotherapy (R-CHOP), which resulted in tumor regression during the follow-up period reported (up to 15 months).

Our patient was referred to the Department of Otorhinolaryngology because of voice change, stridor and dyspnea. Endoscopy and computed tomographic examination showed that the laryngeal stenosis was mainly located in the glottic and subglottic areas. The patient underwent endoscopic $\mathrm{CO}_{2}$ laser lesion resection and dilation. Amyloidosis, a rare cause of laryngeal stenosis, was at the top of our clinical questions for this case. The final pathological diagnosis was DLBCL without amyloidosis. Consequently, the patient was treated with chemotherapy and was doing well and satisfactory with ongoing therapy at the 5-month follow up. To our knowledge, this is the first documented case of laryngeal stenosis caused by primary DLBCL in the English literature, and expands the data on lymphoma as an etiology of laryngeal stenosis.

In our case, the tissue sample showed significant crush and cauterized artifacts due to the $\mathrm{CO}_{2}$ laser treatment, in which it was difficult and challenging to make a definitive diagnosis of lymphoma based on hematoxylin and eosinstained sections. In some cases, this might be misinterpreted as chronic inflammation with crush or cauterized artifacts. Pathologists and clinicians should be aware that lymphomas can be among the etiologies of laryngeal stenosis, and that immunohistochemical, cytogenetic and molecular studies are necessary in order to establish a firm diagnosis.

The mainstay treatment strategies for lymphoma are chemotherapy, radiotherapy or combination of chemo- and radiotherapy rather than surgical treatment. About $60 \%$ of patients with DLBCL received standard chemotherapy, including R-CHOP (11). However, 30-40\% of patients with DLBCL have recurrent or refractory disease that cannot be cured with standard chemotherapy. For patients with high-risk DLBCL, especially high-grade disease with $M Y C$ and $B C L 2$ or BCL6 translocation (so-called 'double/triple hit' DLBCL) $(12,13)$, dose-adjusted rituximab, etoposide, prednisone, vincristine, cyclophosphamide and adriamycin (DAR-EPCH) regimens are commonly used high-dose regimens. Recently, chimeric antigen receptor (CAR-T) therapy, in which the immune checkpoint was blocked, in particular through cytotoxic T-lymphocyte-associated protein 4 (CTLA4) and programmed cell death protein 1 pathway, which was used as an alternative regimen for patients with relapsed or refractory lymphoma, might also provide a new strategy for management of primary laryngeal lymphoma (14).

In summary, we report a rare case of laryngeal stenosis caused by primary DLBCL. DLBCL, or lymphomas in general, may be under-recognized, particularly on biopsy with crush and cauterized artifacts. Prompt tissue biopsy and accurate pathological diagnosis are the keys to treatment and to improving clinical outcomes. The new insight of immunotherapy regimens may expand the therapeutic armamentarium for refractory primary laryngeal lymphomas.

\section{Conflicts of Interest}

All Authors have no conflicts of interest to declare.

\section{Authors' Contributions}

YT wrote the article; JL designed the study, reviewed the slides, made the diagnosis, collected and analyzed the data, and finalized the manuscript; PL reviewed the slides, made the diagnosis and reviewed the article; DC reviewed the article.

\section{References}

1 Tanner K, Anderson C and Smith ME: Nebulizer use in adults with subglottic stenosis: A survey study. Ann Otol Rhinol Laryngol 128: 345-351, 2019. PMID: 30638026. DOI: 10.1177/ 0003489418823797

2 Nouraei SA, Makmur E, Dias A, Butler CR, Nandi R, Elliott MJ and Hewitt R: Validation of the Airway-Dyspnoea-VoiceSwallow (ADVS) scale and Patient-Reported Outcome Measure (PROM) as disease-specific instruments in paediatric laryngotracheal stenosis. Clin Otolaryngol 42: 283-294, 2017. PMID: 27542317. DOI: 10.1111/coa.12729

3 Yu YF, Ling HY, Xiao GS, Sun P, Li MY and Wu WY: Misdiagnosed rare subglottic lesions with bronchial asthma as the initial symptom. Am J Emerg Med 31: 1295.e1-4, 2013. PMID: 23702064. DOI: 10.1016/j.ajem.2013.04.023

4 de Benedictis FM, de Benedictis D, Mirabile L, Pozzi M, Guerrieri A and Di Pillo S: Ground zero: Not asthma at all. Pediatr Allergy Immunol 26: 490-496, 2015. PMID: 26059018. DOI: $10.1111 /$ pai.12421

5 Bielinski C, Luu HS and Mau T: Mucosa-associated lymphoid tissue (MALT) lymphoma presenting as subglottic stenosis: single-agent treatment using rituximab. Otolaryngol Head Neck Surg 150: 334-335, 2014. PMID: 24334958. DOI: 10.1177/ 0194599813515632

6 Kuo JR, Hou YY, Chu ST and Chien CC: Subglottic stenosis induced by extranodal mucosa-associated lymphoid tissue lymphoma. J Chin Med Assoc 74: 144-147, 2011. PMID: 21421212. DOI: $10.1016 /$ j.jcma.2011.01.032 
7 Brake MK, Lee BS, Hoyt BJ and Taylor M: Subglottic stenosis secondary to lymphoplasmacytic lymphoma. Arch Otolaryngol Head Neck Surg 137: 187-189, 2011. PMID: 21339407. DOI: 10.1001/archoto.2010.253

8 Korst RJ: Primary lymphoma of the subglottic airway in a patient with Sjogren's syndrome mimicking high laryngotracheal stenosis. Ann Thorac Surg 84: 1756-1758, 2007. PMID: 17954109. DOI: 10.1016/j.athoracsur.2007.05.075

9 Steffen A, Jafari C, Merz H, Galle J and Berger G: Subglottic MALT lymphoma of the larynx-more attention to the glottis. In Vivo 21: 695-698, 2007. PMID: 17708368.

10 Andratschke M, Stelter K, Ihrler S and Hagedorn H: Subglottic tracheal stenosis as primary manifestation of a marginal zone Bcell lymphoma of the larynx. In Vivo 19: 547-550, 2005. PMID: 15875774 .

11 Coiffier B and Sarkozy C: Diffuse large B-cell lymphoma: RCHOP failure \& What to do? Hematology Am Soc Hematol Educ Program 2016: 366-378, 2016. PMID: 27913503. DOI: 10.1182/asheducation-2016.1.366
12 Chan WC, Lai J, Nakamura S and Rosenwald A: Diffuse large B-cell lymphoma. In: WHO Classification of Tumours of the Digestive System. Lyon, France, IARC Press, pp. 402-405, 2019.

$13 \mathrm{Hu} \mathrm{M}$, Trevino J, Yang L, Cao D, Liu X and Lai J: Primary gastric EBV-positive diffuse large B-cell lymphoma (DLBCL) of the elderly with plasmablastic differentiation. In Vivo 32: 413-417, 2018. PMID: 29475930. DOI: 10.21873 /invivo.11255

14 Zhang J, Medeiros LJ and Young KH: Cancer immunotherapy in diffuse large B-cell lymphoma. Front Oncol 8: 351, 2018. PMID: 30250823. DOI: 10.3389/fonc.2018.00351

Received September 14, 2019

Revised October 5, 2019

Accepted October 10, 2019 